\title{
A STUDY OF HYPOALBUMINAEMIA IN CHRONIC LIVER DISEASE AND ITS CORRELATION WITH DEVELOPMENT OF ESOPHAGEAL VARICES
}

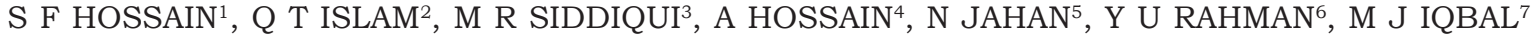

\begin{abstract}
Background: The aim and objective of this study was to evaluate relationship of serum albumin and esophageal varices in chronic liver disease (CLD) admitted in the medicine unit and gastroenterology department of Dhaka Medical College Hospital.

Method: In this cross-sectional study, a total number of 100 randomly selected, clinically diagnosed patients of chronic liver disease were studied from June 2010 to November 2010 (6 months). All patients were assessed as per Child-Pugh class and had full blood count, HBsAg, Anti-HCV antibodies by ELISA, abdominal ultrasound and Endoscopy of upper gastrointestinal tract. Patients were divided into Group A (serum albumin <3.5 gm\%) and Group B (3.55).

Result: Seventy-three male (73\%) and twenty seven female patients (27\%)] with age range of 16 to 75 years were evaluated. Out of 100 patients 24\% were in between 46-55 years age group. 63\% patient fall in child Pugh class A group, 32\% fall in child Pugh class B \& 5\% fall in child Pugh class C. Mean Serum albumin was $3.8 \mathrm{gm} \%$, (range 2.4-4.9). Esophageal varices (EV) were present in 32 patients (32\%) and absent in 68 patients (68\%). Group A had 29 patients (29\% of the total) with 18 patients (62.06\%) having EV. Group B had 71 patients (71\% of the total) with 14 patients (19.71\%) having EV. Sensitivity of hypoalbuminaemia as a marker of EV was 56\% and specificity 83.8\%, positive predictive value $62.06 \%$ and negative predictive value $80.2 \%$ and Odds ratio was 6.6. $P$ value is $<0.001$.

Conclusion: In Group A that is hypoalbuminaemia ( $<3.5 \mathrm{gm} \%)$, the incidence of Esophageal varices was more than Group B that is albumin level (>3.5gm\%). Hypoalbuminemia is a good surrogate marker for the presence of esophageal varices in CLD.
\end{abstract}

Key Words: Chronic liver disease, hypoalbuminaemia, esophageal varices

\section{Introduction:}

Chronic liver disease (CLD) is a common hepatobiliary problem encountered in day to day clinical practice in Bangladesh. CLD can occur at any age \& often causes prolonged morbidity $\&$ is an important cause of premature death. The patient who we come across in the hospital ward is mostly in advanced stage with overt clinical manifestation and/or complication. Among them most important life threatening condition is vomiting out of blood (Haematemesis) \& malaena due to ruptured esophageal varices. Although $90 \%$ of patients with cirrhosis develop varices, only $30 \%$ of them bleed and $30-50 \%$ die of the first episode. ${ }^{1}$ Two thirds of the survivors will rebleed within six months if not treated with prophylactic âblockers or endoscopic therapy. ${ }^{2}$

Albumin (50\%-60\% of total plasma protein), globulin, and fibrinogen make up the major share of plasma proteins with $24 \%-56 \%$ increased risk of death per $2.5 \mathrm{~g} \%$ fall in serum albumin. ${ }^{3,4}$ Child-Pugh score (serum albumin being integral part of the score) predicts advanced liver disease. ${ }^{5}$ Liver produces albumin at a rate of $130-200 \mathrm{mg} / \mathrm{kg} / \mathrm{day}^{3}$ Hypoalbuminemia in cirrhosis is multifactorial and may be due to reduced production (liver parenchyma replaced by fibrous tissue), increased removal by reticuloendothelial system (spleen) or increased loss through gut ${ }^{6}$ (portal gastropathy/enteropathy): all

1. Junior Consultant, Dept. of Medicine, United Hospital Dhaka,

2. Professor (PRL), Dept. of Medicine, Dhaka Medical College,

3. Senior Medical Officer, EECP Heart Therapy, The Medical Centre, Dhaka,

4. Assistant Professor, Dept. of Medicine, Dhaka Medical College,

5. Student, FCPS Medicine P-II Course, Dhaka Medical College,

6. Assistant Registrar, Dept. of Neurology, Dhaka Medical College Hospital,

7. Student, FCPS Medicine P-II Course, Dhaka Medical College,

Bangladesh J Medicine 2011; 22 : 17-20 
related to portal hypertension. Hypoalbuminemia with associated ultrasonographic features e.g. gallbladder wall thickness ${ }^{5}$ and right liver lobe diameter ${ }^{7}$ have been cited as non-endoscopic predictors of esophageal varices. Similarly, Serum Ascitic Albumin Gradient (the difference between the serum and ascetic albumin concentration) i.e. SAAG, is thought to be an indirect marker of portal hypertension, ${ }^{8}$ with a high gradient $(>1.1 \mathrm{~g} / \mathrm{dL})$ indicating portal hypertension and presence of EV.

Portal hypertension (portal pressure $>12 \mathrm{~mm} \mathrm{Hg}$ or $>5 \mathrm{~mm} \mathrm{Hg}$ gradient between the wedged hepatic venous pressure and the free hepatic venous pressure has been shown in animal studies to induce hypoalbuminemia. ${ }^{9}$ Conversely, serum albumin is increased by $20 \%$ when portal pressure is reduced after Trans jugular Intra-hepatic Porto-systemic Shunt Procedure suggesting a link between portal hypertension and hypoalbuminaemia.

\section{Materials and Methods:}

In this cross-sectional study, a total number of 100 randomly selected, clinically diagnosed patients of chronic liver disease were studied for a period of June 2010 to November 2010 (6 months) at medicine units and gastroenterology department of Dhaka Medical College Hospital. Clinically CLD diagnosed interlaying one or more stisgment or child. All patients were assessed as per Child-Pugh class and had full blood count, HBsAg, Anti-HCV antibodies by ELISA, abdominal ultrasound and Endoscopy of upper gastrointestinal tract. Exclusion criteria were patients receiving sclerotherapy, band ligation of $\mathrm{EV}$ and prophylactic treatment for portal hypertension, hypoalbuminemia which in clinically correlated with congenital cardiac failure nephritic syndrome or malnutrition patient refusing to give consent to take part in our study. This study was carried out to correlate between serum albumin and EV in CLD. Patients were divided into Group A (serum albumin $<3.5 \mathrm{gm}$ and Group B (albumin $>3.5 \mathrm{~g} /$ day). Statistical analysis was carried out by using SPSS v16.0 Windows statistical software. Descriptive statistics were used for the interpretation of the findings. Informed and written consent obtained from all patients or their guardian. Formal Ethical Clearance was obtained from the Research Review Committee of Dhaka Medical College and Hospital.

\section{Result:}

Seventy-three male $(73 \%)$ and twenty seven female patients $(27 \%)$ with age range of 16 to 75 years were evaluated. Out of 100 patients $24 \%$ were in between 46-55 years age group. $75 \%$ of CLD were due to Hepatitis B, $7 \%$ due to Hepatitis C, $18 \%$ due to others. $32 \%$ patients have $\mathrm{EV}$ and $68 \%$ patients do not have EV.

Figure-1 shows that majority of CLD patients 63\% fall in child Pugh class A group, followed by $32 \%$ fall in child Pugh class B \& 5\% fall in child Pugh class C.

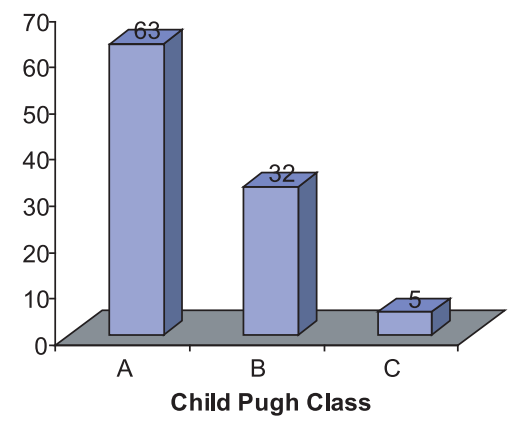

Fig.-1: Distribution of CLD patients in Child Pugh class

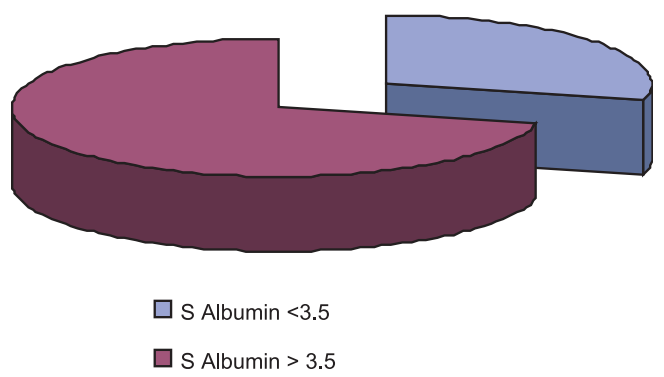

Fig.-2: Prevalence of hypoalbuminaemia in CLD patients

Table-I

Gradings of EV in different Child Pugh class

\begin{tabular}{lcccccc}
\hline Child Pugh class & NO EV (\%) & Grade I (\%) & Grade II (\%) & Grade III (\%) & Grade IV (\%) & Total (\%) \\
\hline A & $47(74.60)$ & $8(12.69)$ & $5(7.93)$ & $1(1.58)$ & $2(3.17)$ & $63(100)$ \\
B & $20(62.5)$ & $2(6.25)$ & $1(3.13)$ & $2(6.25)$ & $7(21.87)$ & $32(100)$ \\
C & $1(20)$ & $0(0)$ & $2(40)$ & $1(20)$ & $1(20)$ & $5(100)$ \\
\hline Total $(\%)$ & $68(68)$ & $10(10)$ & $8(8)$ & $4(4)$ & $10(10)$ & 100 \\
\hline
\end{tabular}


Table-I shows among 100pts of CLD pts 63 pts (63\%) were in Child Pugh class A from which $74.60 \%$ have no varices. 32 pts (32\%) were in Child Pugh class B from which $62.5 \%$ have no varices. 5 pts $(5 \%)$ were in Child Pugh class C from which $40 \%$ have Grade II varices.

Fig.-2 shows maximum $71 \%$ CLD patients have serum albumin $>3.5 \mathrm{gm} / \mathrm{dl}$ and $29 \%$ patients have serum albumin $<3.5 \mathrm{gm} / \mathrm{dl}$.

\section{Table-II}

Frequency of Esophageal varices in group $A$ \& group $B$ in Chronic Liver Disease pts

\begin{tabular}{lcccc}
\hline $\begin{array}{l}\text { Albumin Level } \\
(\mathrm{gm} / \mathrm{dl})\end{array}$ & $\begin{array}{c}\mathrm{EV} \\
\text { Present }(\%)\end{array}$ & $\begin{array}{c}\text { EV } \\
\text { Absent }(\%)\end{array}$ & $\begin{array}{c}\text { Total } \\
(\%)\end{array}$ & $\begin{array}{c}P \\
\text { value }\end{array}$ \\
\hline $\begin{array}{l}\text { Group A } \\
(<3.5 \mathrm{gm} / \mathrm{dl})\end{array}$ & $18(62.06)$ & $11(37.93)$ & $29(29)$ & $<0.001$ \\
$\begin{array}{l}\text { Group B } \\
(>3.5 \mathrm{gm} / \mathrm{d} 1)\end{array}$ & $14(19.71)$ & $57(80.28)$ & $71(71)$ & \\
\hline Total & 32 & 68 & 100 & \\
\hline
\end{tabular}

EV : Esophageal varices, CLD: Chronic liver disease

Table-II shows that in group A $62.06 \%$ have EV while in group B only $19.71 \%$ have $\mathrm{EV}$, So $\mathrm{EV}$ is more in group A in CLD patients. This Table shows $\mathrm{P}$ value is $<0.001$ that is association between hypoalbuminaemia and Esophageal varices is significant. Sensivity: $56 \%$, Specificity: $83.8 \%$, positive predictive value (PPV): 62.06\%, negative predictive value (NPV): $80.2 \%$, odds ratio: 6.6 .

\section{Discussion:}

In this study all the patients were grouped in six age groups. Majority of the study subjects were in between 46-55 years age group $24 \%$ followed by $23 \%$ between $36-45$ years age group. Ahsan $\mathrm{T}$ et al ${ }^{10}$ found $28 \%$ in between 46-55 years age group which coincide with our study. $73 \%$ were male and $27 \%$ female. Male female ratio was 2.7:1. Mahtab et al ${ }^{11}$ found malefemale ratio of $2.97: 1$, which almost coincide with our study. In this study 63\% patient fall in child Pugh class A group, 32\% fall in child Pugh class B \& 5\% fall in child Pugh class $\mathrm{C}$. This study almost coincide with the study of khan $\mathrm{H}$ et al ${ }^{4}$ where $70.1 \%$ patient fall in child Pugh class A group, 24.9\% patient fall in child Pugh class B group, 5.1\% patient fall in child Pugh class C group. Present study shows that $32 \%$ of CLD patients have EV \& 68\% patients did not have EV. Fook-Hong et al ${ }^{12}$ found 53pt (57.60\%) have EV, 39 pt (42.39\%) did not have, Schepis et al found ${ }^{13} 80$ pt (55.9\%) have EV, 63 pt (44.05\%) did not have. This difference may be due to sample size and etiological difference.
In child pugh class A pts, 16pts out of 63 pts(25.40\%) have varices among them 8 pts(12.69\%) have grade I, 47 pts $(74.60 \%)$ have no varices. In child pugh class B pts, 12 pts out of 32 pts (37.50\%) have varices among them 7 pts $(21.88 \%)$ have grade IV, 20 pts $(62.5 \%)$ have no varices. In child pugh class $\mathrm{C}$ pts, 4 pts out of $5(80 \%)$ have varices among them 2 pts (4\%) have grade II, 1 pt (20\%) have no varices.

Present study shows that 29 pt (29\%) out of 100 have hypoalbuminaemia $(<3.5 \mathrm{gm} / \mathrm{dl}$ that is group A) while 71 pts $(71 \%)$ had albumin level $>3.5 \mathrm{gm} / \mathrm{dl}$ that is group B. In group A (Albumin level <3.5 gm/dl), 18 pts $(62.06 \%)$ have $\mathrm{EV}$, and 11 patient $(37.93 \%)$ did not have EV. In group B (Albumin level >3.5 gm/dl), 14 pts $(19.71 \%)$ have $\mathrm{EV}$, and 57 patient $(80.28 \%)$ did not have EV. Mean serum albumin level was $3.8 \mathrm{gm} /$ dl. Khan $\mathrm{H}$ et $\mathrm{al}{ }^{4}$ found 57 pts $(28.9 \%)$ out of 197 have hypoalbuminaemia $(<3.5 \mathrm{gm} / \mathrm{dl})$. Among them 35 pts (61.4\%) have EV, while 140 pts (71.1\%) had albumin level $>3.5 \mathrm{gm} / \mathrm{dl}$ ) with 28 having EV (20\%). This consistent with the present study. From this study, hypoalbuminaemia $(<3.5 \mathrm{gm} / \mathrm{dl})$ is $56 \%$ sensitive \& $83.8 \%$ specific for presence of $\mathrm{EV}$ with positive predictive value of $62.06 \% \&$ negative predictive value of $80.2 \%$ and odds ratio is 6.6 and $P$ value is $<0.001$ (Table 2) that is association between hypoalbuminaemia and Esophageal varices is significant. This study almost coincide with the study of khan $\mathrm{H}$ et al 4 which shows that hypoalbuminaemia $(<3.5 \mathrm{gm} / \mathrm{dl})$ is $53.2 \%$ sensitive $\& 91 \%$ specific predictor of $\mathrm{EV}$ with positive predictive value of $73.3 \%$ and negative predictive value of $80.8 \%$ and odds ratio of 11.57 . Zein et al ${ }^{14}$ in a study of 183 patients with primary sclerosing cholangitis, found 66\% sensitivity, $80 \%$ specificity, 53.4\% PPV, $87.2 \%$ NPV and odd ratio of 7.8 for albuminaemia of $<3.5$ gm\%; almost similar to our results. The minor differences in figures could be explained on the basis of difference in etiology of the study population and sample size. khan $\mathrm{H}$ et al ${ }^{4}$ used study population with uniform etiology of infective hepatitis \& Zein et $\mathrm{al}^{14}$ in a study of 183 patients with primary patients with CLD of diverse etiologies. The minor differences in sclerosing cholangitis, Bressler et $\mathrm{al}^{15}$ found albuminemia of $<4 \mathrm{gm} \%$ as an independent risk factor for EV with odd ratio of 6.02 We used albuminemia of $<3.5$ gm\% while Schepis et al ${ }^{13}$ and Sarwar et al 16 used level of $<2.95 \mathrm{gm} \%$ to predict the presence of EV. Odds ratio was 6.6 and the difference could be explained by $<3.5$ gm\% albumin level we used and our study population with CLD with diverse etiology. Specificity of $83.8 \%$ and PPV of $62.06 \%$ suggests that hypoalbuminemia is a good indicator of EV. However, 
low sensitivity of hypoalbuminemia (56\%) and NPV of $80.2 \%$ indicates that absence of hypoalbuminema does not rule out EV.

\section{Conclusion:}

Patients with chronic liver disease frequently undergo endoscopy of upper GIT to detect EV. Doing endoscopy in all patients of CLD will increase socio-economic and medical load because of the rising numbers of such patients. Therefore, there is a particular need for a noninvasive predictor for the presence of $\mathrm{EV}$ to ease the medical, social and economic burden of the disease. Many previous studies have documented good predictive value of various non-endoscopic variables for the presence or absence of varices, but available data in our country is limited. We consider simple, commonly available parameter serum albumin. From this study it is assumed that hypoalbuminaemia is a good non-endoscopic marker for the presence of esophageal varices.

Conflict of interest: We have no conflict of interest.

\section{References:}

1. Jalan R, Hayes PC. UK guidelines on the management of haemorrhage in cirrhotic patients. British Society of Gastroenterology. Gut 2000;46 Supp1 3-4:III1-III15.

2. Boyer T. Natural history of portal hypertension. Clin Liver Dis 1997;1:31- 44.

3. Rainey TG, Read CA. Pharmacology of colloids and crystalloids. In: Chernow B, editor. The Pharmacologic approach to the critically ill patient. Baltimore MD: Williams and Wilkins, 1994:.27290 .

4. Khan H, Iman N. Hypoalbuminaemia ; a marker of esophageal varices in chronic liver diseasedue to Hepatitis B\& C. Rawal Med J 2009 ; 34: 98-102.

5. Galip E, Ömer O, Salih AU, Mustafa Y, Zeki K, Yücel B. Gallbladder wall thickening as a sign of esophageal varices in chronic liver disease. Turkish Gastroenterol 1999;10:11-14.

6. Torres E, Barros P, Calmet F. Correlation between serum-ascites albumin concentration gradient and endoscopic parameters of portal hypertension. Am
J Gastroenterol 1998;93:2172-8.

7. Alempijevic T, KEVacevic N. Right liver lobe diameter: albumin ratio: a new non-invasive parameter for prediction of oesophageal varices in patients with liver cirrhosis (preliminary report). Gut 2007;56:1166-67.

8. B.B Das, A Purohit, U Acharya and E Treskova.Serum - Ascites Albumin Gradient: A predictor of esophageal varices with ascites.Indian Journal of Paediatrics 2001;68:511-514.

9. Nava MP, Aller MA, Vega M, Prieto I, Valdes F, Arias J. Altered proteinogram in short term portal vein stenosed rats. Chinese Physiol. 2002;45(2):89-93.

10. Ahsan T,Ahsan M.Kamal MM,Hossain KJ,Haque ME,Islam SN. Lifestyle, Nutritional status and seroclinical profile of liver cirrhotic patients Bangladesh Medical Journal 2007;36(2):44-47.

11. Mahtab MA, Rahman S, Kamal M, Shrestha A, Akbar SM, Karim F, Dhar SC. Low viral load does not exclude significant liver damage in patients with chronic HBV infection in Bangladesh. BSMMU J. 2008; 1(1): 19-21.

12. Merli M, Nicolini G, Angeloni S, et al. Incidence and natural history of small esophageal varices in cirrhotic patients. J Hepatol 2003;38:266-272.

13. Schepis F, Camma C, Niceforo D, Magnano A, Pallio $\mathrm{S}$, Cinquegrani $\mathrm{M}$, et al. Which Patients With Cirrhosis Should Undergo Endoscopic Screening for Esophageal Varices Detection? Hepatology 2001;33:333-38.

14. Zein CO, Lindor KD, Angulo P. Prevalence and predictors of esophageal varices in patients with primary sclerosing cholangitis. Hepatology 2004; 39:204-10.

15. Bressler B, Pinto R, E1-Ashry D, Heathcote EJ. Which patients with primary biliary cirrhosis or primary sclerosing cholangitis should undergo endoscopic screening for esophageal varices detection. Gut 2005;54: 407-10.

16. Sarwar S, Khan AA, Butt AK, Shafqat F, Malik K, Ahmad I, et al. Non-endoscopic prediction of esophageal varices in cirrhosis. J Coll Physicians Surg Pak 2005;15:528-31. 